\title{
Numerical Data Containing One Parameter and Chance Error: Evaluation of the Parameter by Convergence of Statistic
}

\author{
Dhritikesh Chakrabarty \\ Department of Statistics, Handique Girls' College, Guwahati, Assam, India, \\ dhritikesh.c@ rediffmail.com, dhritikeshchakrabarty@gmail.com
}

\begin{abstract}
For the purpose of determining error-free estimate i.e. the true value of the parameter from observed data containing the parameter itself and chance error, one method has been developed for determining the value of the same since the existing statistical methods of estimation in such situation fail in finding out of such value of the parameter. The method developed here is based on the convergence of statistic i.e. some function of numerical data. The method has been applied in determining the central tendency of each of annual maximum and annual minimum of the ambient air temperature at Guwahati.
\end{abstract}

Key words: 1. Parameter; 2. chance error, 3. observed numerical data; 4. convergence of statistic; 5. determination of parameter

\section{Introduction}

There are many situations where observations

$$
X_{1}, X_{2}, \ldots \ldots \ldots, X_{n}
$$

are composed of some parameter and chance errors i.e.

$$
X_{i}=\mu+\varepsilon_{i} \quad, \quad(i=1,2, \ldots \ldots \ldots, n)
$$

where (i) $\mu$ is the parameter

\& (ii) $\varepsilon_{i}$ is the chance error associated with $X_{i}$

[Chakrabarty (2014a, 2014b, 2014c, 2015a, 2015b, 2015c, 2015d, 2015e]. 
Here,

$$
\mu=T\left(X_{i}\right) \quad, \quad(i=1,2, \ldots \ldots \ldots \ldots, n)
$$

where $T\left(X_{i}\right)$ is the true part of $X_{i}$.

The existing methods of estimation namely least squares method, maximum likelihood method, minimum variance unbiased method, method of moment and method of minimum chi-square [Aldrich,1930; Anders ,1999; Barnard,1949; Birnbaum,1962; Ivory,1825; Kendall \& Stuart, 1977; Lehmann \& Casella George,1998; Lucien, 1990; Walker \& Lev,1965] provides

$$
{ }^{-} X=(1 / n) \sum_{i=1}^{n} X_{i}
$$

as estimator of the parameter $\mu$.

On the other hand, equation (1.1) implies that

which further implies

$$
\sum_{i=1}^{n} X_{i}=n \mu \stackrel{+}{+} \sum_{i=1}^{n} \varepsilon_{i}
$$

$$
{ }^{-} X=\mu+\varepsilon
$$

where

$$
\bar{\varepsilon}=(1 / n) \sum_{i=1}^{n} \varepsilon_{i}
$$

Thus, the estimator $\bar{X}$ of the parameter $\mu$ suffers from an error $\varepsilon$ given by (1.5).

This error however may need not necessarily be zero.

In other words, none of these methods can provide the true value of the parameter $\mu$.

Recently, some studies have been done on determining the true value of the parameter $\mu$ involved in the model described by (1.1) [Chakrabarty (2014a , 2014b , 2014c , 2015a , 2015b , 2015c , 2015d , 2015e , 2015f , 2016a , 2016b) ;Bordoloi \& Chakrabarty (2015 , 2015 - 16 , 2016a , 2016b , 2016c , 2016 - 17)]. In the studies some methods have been developed for determining the true value of the parameter $\mu$ when 
$\varepsilon_{i}$ occurs due to chance only. One of them is based on computing sequence of interval value of $\mu$ with decreasing length of interval and then to find out the shortest interval value of $\mu$ [Chakrabarty (2014a, $2014 b, 2014 c, 2015 d)$; Bordoloi \& Chakrabarty $(2016 a, 2016 b]$. The other one is based on stable mid range and median. However, these methods may not be always successful in determining the true value $\mu$ [Chakrabarty ,2015b ; Bordoloi \& Chakrabarty,2015)]. For this reason, attempt has here been made on searching for one more method of determining the true value $\mu$. The method derived here is based on the convergence of statistic i.e. some function of the available numerical data. This paper is based on the derivation of this method and on one numerical application of the method in determining the central tendency of each of annual maximum and annual minimum of ambient air temperature at Guwahati.

\section{Method of Determination of Parameter $\mu$}

The model considered here is

$$
X_{i}=\mu+\varepsilon_{i} \quad, \quad(i=1,2, \ldots \ldots \ldots, n)
$$

where

(i) $X_{1}, X_{2}, \ldots \ldots \ldots \ldots, X_{n}$ are observed data on the variable $X$,

(ii) $\mu$ is the parameter

and (iii) $\varepsilon_{i}$ is the chance error associated with $X_{i}$.

\subsection{Derivation of Method}

From Equations described by (2.1),

$$
\left|X_{i}\right| X_{i}=\mu\left|X_{i}\right|+\varepsilon_{i}\left|X_{i}\right| \quad, \quad(i=1,2, \ldots \ldots \ldots, n)
$$

which implies,

$$
\sum_{i=1}^{n}\left|X_{i}\right| X_{i}=\mu \sum_{i=1}^{n}\left|X_{i}\right|+\sum_{i=1}^{n} \varepsilon_{i}\left|X_{i}\right|
$$

which implies, 


$$
\left.\mu=\left(\sum_{i=1}^{n}\left|X_{i}\right| X_{i}\right) /\left(\sum_{i=1}^{n}\left|X_{i}\right|\right)+\underset{i=1}{n} \underset{i=1}{n} \sum_{i}\left|X_{i}\right|\right) /\left(\sum\left|X_{i}\right|\right)
$$

Now,

$$
\varepsilon_{i}, \quad(i=1,2, \ldots \ldots \ldots \ldots, n)
$$

being chance errors (i.e. random errors), assume both positive and negative values in random manner.

Hence, the series $\left\{U_{n}\right\}$

where $\quad U_{n}=\sum_{i=1}^{n} \varepsilon_{i}\left|X_{i}\right|$

cannot be cannot be monotonically increasing but oscillatory.

Also, the series $\left\{V_{n}\right\}$

where $\quad V_{n}=\sum_{i=1}^{n}\left|X_{i}\right|$

is strictly monotonically increasing.

Hence, the series $\left\{Z_{n}\right\}$ converges to 0 as $n \rightarrow \infty$

where

$$
Z_{n}=U_{n} / V_{n}
$$

$(n=1,2,3,4, \ldots$

i.e. $\quad\left(U_{n} / V_{n}\right) \rightarrow 0$ as $n \rightarrow \infty$

i.e. $\quad\left\{\left(\sum_{i=1}^{n}\left|X_{i}\right| \varepsilon_{i}\right) /\left(\sum_{i=1}^{n}\left|X_{i}\right|\right)\right\} \rightarrow 0$ as $n \rightarrow \infty$

Accordingly,

$$
\left\{\left(\sum_{i=1}^{n}\left|X_{i}\right| X_{i}\right) /\left(\sum_{i=1}^{n}\left|X_{i}\right|\right)\right\} \rightarrow \mu \text { as } n \rightarrow \infty
$$

Thus, the value towards which the computed values of 


$$
\left\{\left(\sum_{i=1}^{n}\left|X_{i}\right| X_{i}\right) /\left(\sum_{i=1}^{n}\left|X_{i}\right|\right)\right\}
$$

converge is the value of $\mu$.

Again from (2.1),

$$
X_{i}{ }^{3}=\mu X_{i}{ }^{2}+\varepsilon_{i} X_{i}{ }^{2}, \quad(i=1,2, \ldots \ldots \ldots \ldots, n)
$$

which implies,

$$
\sum_{i=1}^{n} X_{i}^{3}=\mu \sum_{i=1}^{n} X_{i}^{2}+\sum_{i=1}^{n} \varepsilon_{i} X_{i}^{2}
$$

which further implies,

$$
\left.\mu=\left(\sum_{i=1}^{n} X_{i}^{3}\right) /\left(\sum_{i=1}^{n} X_{i}^{2}\right)+{ }_{i=1}^{n} \varepsilon_{i} X_{i}^{2}\right) /\left(\sum_{i=1}^{n} X_{i}^{2}\right)
$$

As earlier the series

$$
\left\{\sum_{i=1}^{n} \varepsilon_{i} X_{i}^{2}\right\}
$$

cannot be monotonically increasing but oscillatory.

Also, the series

$$
\left\{\sum_{i=1}^{n} X_{i}^{2}\right\}
$$

is strictly monotonically increasing.

Hence,

$$
\left\{\left(\sum_{i=1}^{n} \varepsilon_{i} X_{i}^{2}\right) /\left(\sum_{i=1}^{n} X_{i}^{2}\right)\right\} \rightarrow 0 \text { as } n \rightarrow \infty
$$

Accordingly,

$$
\left\{\left(\sum_{i=1}^{n} X_{i}^{3}\right) /\left(\sum_{i=1}^{n} X_{i}^{2}\right)\right\} \rightarrow \mu \text { as } n \rightarrow \infty
$$


Thus, the value towards which the computed values of

$$
\underset{i=1}{\left\{\left(\sum_{i=1}^{n} X_{i}^{3}\right) /\left(\sum_{i=1}^{n} X_{i}^{2}\right)\right\}}
$$

converge is the value of $\mu$.

Similarly, it can be shown that

$$
\underset{i=1}{\left\{\left(\sum_{i=1}^{n} X_{i}^{5}\right) /\left(\sum_{i} X_{i}^{4}\right)\right\} \rightarrow \mu \text { as } n \rightarrow \infty}
$$

which means that the value towards which the computed values of

$$
\begin{array}{ll}
\left\{\left(\sum X_{i}{ }^{5}\right) /(\right. & n \\
i=1 & i=1
\end{array}
$$

converge is the value of $\mu$

i.e.

$$
\underset{i=1}{\left\{\left(\sum_{i=1}^{n} X_{i}^{5}\right) /\left(\sum_{i=1}^{n} X_{i}^{4}\right)\right\} \rightarrow \mu \text { as } n \rightarrow \infty}
$$

In general,

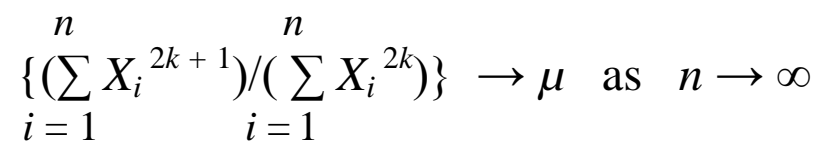

(for $k=1,2,3$,

which means that the value towards which the computed values of

$$
\left.\left.\sum_{i=1}^{n} \sum_{i}^{2 k+1}\right) /\left(\sum_{i} X_{i}^{2 k}\right)\right\}
$$

converge is the value of $\mu$

(for $k=1,2,3$, ...).

\section{Note:}

(1) In order to determine the value of $\mu$, it is required to compute the converging values of at 
least two of the series

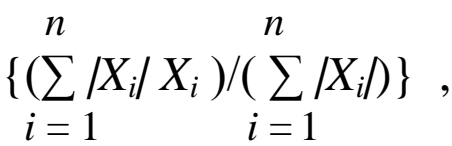

$$
\begin{aligned}
& \left\{\left(\sum_{i=1}^{n} X_{i}^{3}\right) /\left(\sum_{i=1}^{n} X_{i}^{2}\right)\right\}, \\
& \underset{i=1}{\left\{\left(\sum_{i=1}^{n} X_{i}^{5}\right) /\left(\sum_{i=1}^{n} X_{i}^{4}\right)\right\}}
\end{aligned}
$$

etc.

The common value of them is the value of $\mu$.

(2) If the series are found to converge but fail to yield a common converging point for the available data then it is to be understood that the data are insufficient for obtaining the value of $\mu$.

(3) If the series are found either not to converge or to converge to different points then it is to be understood that the errors involved in the data are not only due to chance but also due to some assignable cause(s). Consequently, the data do not follow the model described by (2.1). In this case the value of $\mu$ cannot be determined from the given data.

\section{Application to Numerical Data}

Numerical data considered here are the data on each of annual maximum \& annual minimum of ambient air temperature at Guwahati.

\subsection{Annual Maximum Temperature at Guwahati}

The following table shows the data on annual maximum of ambient air temperature, occurred in temperature periodic year (TPR), at Guwahati: 
Table-3.1.1

Observed Value on Annual Maximum of Ambient Air Temperature (in Degree Celsius)

\begin{tabular}{|c|c|c|c|c|c|}
\hline $\begin{array}{l}\text { TPR No } \\
\quad(i)\end{array}$ & $\begin{array}{c}\text { Observed } \\
\text { Value }\left(X_{i}\right)\end{array}$ & $\begin{array}{c}\text { Date } \\
\text { of occurrence }\end{array}$ & $\begin{array}{l}\text { TPR No } \\
\quad(i)\end{array}$ & $\begin{array}{c}\text { Observed } \\
\text { Value }\left(X_{i}\right)\end{array}$ & $\begin{array}{c}\text { Date } \\
\text { of occurrence }\end{array}$ \\
\hline 1 & 37.1 & 1969, May, 20 & 23 & 37.4 & 1991, July, 20 \\
\hline 2 & 36.6 & 1970, April,01 & 24 & 39.4 & 1992, April, 16 \\
\hline 3 & 36.0 & 1971, March, 27 & 25 & 36.4 & 1993, September, 08 \\
\hline 4 & 35.7 & 1972, July, 14 & 26 & 38.1 & 1994, May, 07 \\
\hline 5 & 39.0 & 1973, April,10 & 27 & 36.3 & 1995, May, 14 \\
\hline 6 & 36.1 & 1974, August, 14 & 28 & 39.9 & 1996, April, 19 \\
\hline 7 & 39.2 & 1975, April, 10 & 29 & 37.4 & 1998, May 21 \\
\hline 8 & 39.0 & 1976, April,17 & 30 & 37.5 & 2000, May, 13 \\
\hline 9 & 35.3 & 1977, August, 14 & 31 & 36.7 & 2001, April,07 \\
\hline 10 & 36.8 & 1978, May, 19 & 32 & 35.7 & 2002, September, 20 \\
\hline 11 & 38.6 & 1979, March, 27 & 33 & 37.4 & 2003, July, 26 \\
\hline 12 & 35.1 & 1980, July, 01 & 34 & 38.0 & 2004, March, 28 \\
\hline 13 & 35.8 & 1981, June, 21 & 35 & 36.6 & 2005, July, 30 \\
\hline 14 & 36.5 & 1982, May, 26 & 36 & 38.0 & 2006, August, 11 \\
\hline 15 & 36.7 & 1983, April, 06 & 37 & 37.3 & 2007, May, 06 \\
\hline 16 & 37.2 & 1984, April, 06 & 38 & 37.3 & 2008, August, 08 \\
\hline 17 & 36.5 & 1985, April,26 & 39 & 38.0 & 2009, May, 23 \\
\hline 18 & 38.4 & 1986, April,03 & 40 & 37.2 & 2010, July, 03 \\
\hline 19 & 37.2 & 1987, May, 19 & 41 & 37.3 & 2011, August, 30 \\
\hline 20 & 36.4 & 1988, August, 03 & 42 & 37.4 & 2012, April,03 \\
\hline 21 & 36.7 & 1989, July, 23 & 43 & 38.8 & 2013, June, 12 \\
\hline 22 & 36.0 & 1990, September, 02 & & & \\
\hline
\end{tabular}

Here, data are assumed to follow the model

$$
X_{i}=\mu+\varepsilon_{i} \quad, \quad(i=1,2, \ldots \ldots \ldots ., 43)
$$

where $\mu$ is central tendency of annual maximum and $\varepsilon_{i}$ is the chance error.

Determination of Value of $\mu$ (the central tendency of annual maximum)

In order to determine the value of $\mu$, let us construct the following table (Table - 3.1.2): 
Table-3.1.2

\begin{tabular}{|c|c|c|c|}
\hline $\begin{array}{l}\text { TPR No } \\
(n)\end{array}$ & $(1 / n) \sum_{i=1}^{N} X_{i}$ & $\left(\sum_{i=1}^{n}\left|X_{i}\right| X_{i}\right) /\left(\sum_{i=1}^{n}\left|X_{i}\right|\right)$ & $\left(\sum_{i=1}^{n} X_{i}^{3}\right) /\left(\sum_{i=1}^{n} X_{i}^{2}\right)$ \\
\hline 1 & 37.1 & 37.1 & 37.1 \\
\hline 2 & 36.85 & 36.8516960651289 & 36.85339197413815 \\
\hline 3 & 36.56666666666667 & 36.5721969006381 & 36.57771792909718 \\
\hline 4 & 36.35 & 36.35804676753783 & 36.36611267275265 \\
\hline 5 & 36.88 & 36.91681127982646 & 36.95460568258939 \\
\hline 6 & 36.75 & 36.78308390022676 & 36.81728895393352 \\
\hline 7 & 37.1 & 37.14790142472083 & 37.19681123546356 \\
\hline 8 & 37.3375 & 37.38972212922665 & 37.4423855534096 \\
\hline 9 & 37.11111111111111 & 37.1688622754491 & 37.22734453537827 \\
\hline 10 & 37.08 & 37.13225458468177 & 37.18531227485068 \\
\hline 11 & 37.21818181818182 & 37.27063996091842 & 37.32345261033122 \\
\hline 12 & 37.04166666666667 & 37.09923509561305 & 37.15733893409643 \\
\hline 13 & 36.94615384615385 & 37.00239433687279 & 37.05945488050191 \\
\hline 14 & 39.75492307692308 & 36.96691176470588 & 37.02044136198278 \\
\hline 15 & 36.9 & 36.94921409214092 & 36.99933769782885 \\
\hline 16 & 36.91875 & 36.96500761808024 & 37.01205496804934 \\
\hline 17 & 36.89411764705882 & 36.93794642857143 & 36.98260915731879 \\
\hline 18 & 36.97777777777778 & 37.02229567307692 & 37.06742469373477 \\
\hline 19 & 36.98947368421053 & 37.03170176437109 & 37.07447394670228 \\
\hline 20 & 36.96 & 37.00059523809524 & 37.0418003249626 \\
\hline 21 & 36.94761904761905 & 36.98637711045238 & 37.0257583787986 \\
\hline 22 & 36.90454545454545 & 36.94264071930041 & 36.98143635353122 \\
\hline 23 & 36.92608695652174 & 36.96278111385847 & 37.00008635823409 \\
\hline 24 & 37.02916666666667 & 37.07083380218296 & 37.11317016164894 \\
\hline 25 & 37.004 & 37.04443843908767 & 37.08559714804372 \\
\hline 26 & 37.04615384615385 & 37.08619186046512 & 37.12681939855694 \\
\hline 27 & 37.01851851851852 & 37.0576388194097 & 37.09740477025501 \\
\hline 28 & 37.12142857142857 & 37.16675004810468 & 37.21290128269644 \\
\hline 29 & 37.13103448275862 & 37.1748514115899 & 37.21943905402664 \\
\hline 30 & 37.14333333333333 & 37.18579377187472 & 37.22896066790021 \\
\hline 31 & 37.12903225806452 & 37.17030408340573 & 37.21230799041302 \\
\hline 32 & 37.084375 & 37.12607230133985 & 37.16856013878224 \\
\hline 33 & 37.09393939393939 & 37.13444163058574 & 37.17587989511678 \\
\hline 34 & 37.12058823529412 & 37.16050233737422 & 37.20106161435744 \\
\hline 35 & 37.10571428571429 & 37.14470624470624 & 37.18437088190402 \\
\hline 36 & 37.13055555555556 & 37.16902072267525 & 37.20807614871881 \\
\hline 37 & 37.13513513513514 & 37.17257641921397 & 37.21058016114304 \\
\hline 38 & 37.13947368421053 & 37.1759441649543 & 37.21295137212552 \\
\hline 39 & 37.16153846153846 & 37.19755054164079 & 37.23403261077035 \\
\hline 40 & 37.1625 & 37.19761183989236 & 37.2331808822798 \\
\hline 41 & 37.16585365853659 & 37.20011812573829 & 37.23482089083036 \\
\hline 42 & 37.17142857142857 & 37.20490648219318 & 37.23879865987883 \\
\hline 43 & 37.2093023255814 & 37.2435875 & 37.27823992855146 \\
\hline
\end{tabular}


In Table-3.1.2, it is found that the values of the two functions

$$
\underset{i=1}{\left.\left(\sum_{i=1}^{n}\left|X_{i}\right| X_{i}\right) /\left(\sum_{i=1}^{n}\left|X_{i}\right|\right) \quad \& \quad \sum_{i=1}^{n} X_{i}^{3}\right) /\left(\sum_{i=1}^{n} X_{i}^{2}\right)}
$$

are approaching $37.2435875 \& 37.27823992855146$ respectively. Hence, the true value of the central tendency of annual maximum of the ambient air temperature at Guwahati can be taken as 37.2 Degree Celsius (being the common value of them).

\subsection{Annual Minimum Temperature at Guwahati}

The following table shows the data on annual maximum of ambient air temperature, occurred in temperature periodic year (TPR), at Guwahati.

Table-3.2.1

\begin{tabular}{|c|c|c|c|c|c|}
\hline $\begin{array}{l}\text { TPR No } \\
\text { (i) }\end{array}$ & $\begin{array}{c}\text { Observed } \\
\text { Value }\left(Y_{i}\right)\end{array}$ & $\begin{array}{c}\text { Date } \\
\text { of occurrence }\end{array}$ & $\begin{array}{l}\text { TPR No } \\
\quad(i)\end{array}$ & $\begin{array}{c}\text { Observed } \\
\text { Value }\left(Y_{i}\right)\end{array}$ & $\begin{array}{c}\text { Date } \\
\text { of occurrence }\end{array}$ \\
\hline 1 & 6.6 & 1969, December, 27 & 23 & 5.9 & 1992, January, 05 \\
\hline 2 & 5.9 & $\begin{array}{c}\text { 1971, January, } 31 \\
\text { \& February, } 01\end{array}$ & 24 & 8.4 & 1993, February, 23 \\
\hline 3 & 8.2 & 1972, January,21 & 25 & 7.8 & 1993, December, 27 \\
\hline 4 & 5.0 & 1973, February, 03 & 26 & 7.5 & 1995, January, 22 \\
\hline 5 & 6.3 & 1974, February, 07 & 27 & 9.4 & 1996, January, 19 \\
\hline 6 & 7.4 & 1975, January, 19 & 28 & NA & NA \\
\hline 7 & 6.6 & 1976, January, 22 & 29 & $\mathrm{NA}$ & NA \\
\hline 8 & 6.2 & 1977, January, 30 & 30 & NA & NA \\
\hline 9 & 7.3 & 1978, January, 12 & 31 & 8.3 & 2000, February, 28 \\
\hline 10 & 6.2 & 1979, January, 09 & 32 & 8.9 & 2001, January, 08 \\
\hline 11 & 6.4 & 1980, February, 08 & 33 & 8.6 & 2002, January, 26 \\
\hline 12 & 7.5 & 1981, January, 10 & 34 & 8.0 & 2003, January, 16 \\
\hline 13 & 8.3 & 1982, February, 07 & 35 & 7.9 & 2004, February, 04 \\
\hline 14 & 4.9 & 1983, January, 06 & 36 & 6.7 & 2004, December, 27 \\
\hline 15 & 6.1 & 1984, January, 30 & 37 & 9.6 & 2006, January, 12 \\
\hline 16 & 7.8 & 1985, January, 19 & 38 & 6.4 & 2007, January, 18 \\
\hline 17 & 8.6 & 1986, January, 20 & 39 & 7.8 & 2008, February, 03 \\
\hline 18 & 7.7 & 1987, January, 05 & 40 & 9.9 & 2009, January, 07 \\
\hline 19 & 9.2 & 1988, January, 01 & 41 & 8.6 & 2010, January , 03 \\
\hline 20 & 6.7 & 1989, January, 14 & 42 & 7.0 & 2011, January, 21 \\
\hline 21 & 8.6 & 1989, December, 31 & 43 & 6.4 & 2012, January, 15 \\
\hline 22 & 7.4 & 1991, January, 20 & 44 & 5.6 & 2013, January, 11 \\
\hline
\end{tabular}

Observed Value on Annual Minimum of Ambient Air Temperature (in Degree Celsius) 
These data are assumed to follow the model

$$
Y_{i}=\mu^{\prime}+\varepsilon_{i}^{\prime}, \quad(i=1,2,
$$

where $\mu^{\prime}$ is the central tendency of annual minimum and $\varepsilon_{i}{ }^{\prime}$ is the chance error.

Determination of Value of $\mu^{\prime}$ (the central tendency of annual minimum)

In order to determine the value of $\mu^{\prime}$, let us construct the following table (Table - 3.2.2):

Table-3.2.2

\begin{tabular}{|c|c|c|c|}
\hline $\begin{array}{l}\text { TPR No } \\
\quad(n)\end{array}$ & $(1 / n) \sum_{i=1}^{N} Y_{i}$ & $\left(\sum_{i=1}^{n}\left|Y_{i}\right| Y_{i}\right) /\left(\sum_{i=1}^{n}\left|Y_{i}\right|\right)$ & $\left(\sum_{i=1}^{n} Y_{i}{ }^{3}\right) /\left(\sum_{i=1}^{n} Y_{i}{ }^{2}\right)$ \\
\hline 1 & 6.6 & 6.6 & 6.6 \\
\hline 2 & 6.6 & 6.6 & 6.6 \\
\hline 3 & 6.366666666666667 & 6.383769633507853 & 6.400155827113918 \\
\hline 4 & 6.825 & 6.929304029304029 & 7.039905904741767 \\
\hline 5 & 6.46 & 6.630650154798762 & 6.801788299014801 \\
\hline 6 & 6.433333333333333 & 6.576683937823834 & 6.723335696840778 \\
\hline 7 & 6.571428571428571 & 6.709130434782609 & 6.843399650055084 \\
\hline 8 & 6.575 & 6.695437262357414 & 6.813294338122551 \\
\hline 9 & 6.533333333333333 & 6.643197278911565 & 6.752941477650914 \\
\hline 10 & 6.61 & 6.715733736762481 & 6.818614133495528 \\
\hline 11 & 6.572727272727273 & 6.671507607192254 & 6.769314812895201 \\
\hline 12 & 6.558333333333333 & 6.649428208386277 & 6.740408171064952 \\
\hline 13 & 6.630769230769231 & 6.723433874709977 & 6.814131410035199 \\
\hline 14 & 6.75 & 6.861904761904762 & 6.971987046032848 \\
\hline 15 & 6.6266666666666667 & 6.765191146881288 & 6.898007316420308 \\
\hline 16 & 6.59375 & 6.726729857819905 & 6.856165541730664 \\
\hline 17 & 6.664705882352941 & 6.800617828773169 & 6.930691360267875 \\
\hline 18 & 6.772222222222222 & 6.927563576702215 & 7.076892015110069 \\
\hline 19 & 6.821052631578947 & 6.973456790123457 & 7.117770204479065 \\
\hline 20 & 6.94 & 7.121037463976945 & 7.296078510724403 \\
\hline 21 & 6.928571428571429 & 7.101649484536082 & 7.270182620561507 \\
\hline 22 & 7.004545454545455 & 7.185269305645685 & 7.359009257168661 \\
\hline 23 & 7.021739130434783 & 7.195108359133127 & 7.360940955757696 \\
\hline 24 & 6.975 & 7.149462365591398 & 7.318448889557327 \\
\hline 25 & 7.032 & 7.209215017064846 & 7.378663068692894 \\
\hline 26 & 7.061538461538462 & 7.234313725490196 & 7.397962686904278 \\
\hline 27 & 7.077777777777778 & 7.244740973312402 & 7.402108388047412 \\
\hline 28 & 7.160714285714286 & 7.345785536159601 & 7.521968591079758 \\
\hline 29 & NA & NA & NA \\
\hline 30 & NA & NA & NA \\
\hline 31 & NA & NA & NA \\
\hline 32 & 7.220689655172414 & 7.411843361986628 & 7.592297878920646 \\
\hline
\end{tabular}


Table-3.2.2 Continued

\begin{tabular}{|c|c|c|c|}
\hline $\begin{array}{c}\text { TPR No } \\
(n)\end{array}$ & $(1 / n) \sum_{i=1}^{n} Y_{i}$ & $\left(\sum_{i=1}^{n}\left|Y_{i}\right| Y_{i}\right) /\left(\sum_{i=1}^{n}\left|Y_{i}\right|\right)$ & $\left.\sum_{i=1}^{n} Y_{i}^{3}\right) /\left(\sum_{i=1}^{n} Y_{i}^{2}\right)$ \\
\hline 33 & 7.266666666666667 & 7.458715596330275 & 7.638134071340713 \\
\hline 34 & 7.290322580645161 & 7.47787610619469 & 7.651837869822485 \\
\hline 35 & 7.309375 & 7.492133390337751 & 7.660675869231515 \\
\hline 36 & 7.290909090909091 & 7.470074812967581 & 7.636681689200467 \\
\hline 37 & 7.358823529411765 & 7.551798561151079 & 7.732444190403607 \\
\hline 38 & 7.331428571428571 & 7.52307092751364 & 7.704172149066006 \\
\hline 39 & 7.3444444444444444 & 7.531240544629349 & 7.707100027118508 \\
\hline 40 & 7.413513513513514 & 7.616733503463361 & 7.809971425426106 \\
\hline 41 & 7.444736842105263 & 7.646624248851184 & 7.836982197917004 \\
\hline 42 & 7.433333333333333 & 7.631010693342532 & 7.818443380661143 \\
\hline 43 & 7.4075 & 7.604421194735066 & 7.792657964929722 \\
\hline 44 & 7.363414634146341 & 7.567240808214641 & 7.762559366177146 \\
\hline
\end{tabular}

NA means Not Available

In Table-3.2.2, it is found that the values of the two functions

$$
\left.\underset{i=1}{\left(\sum_{i=1}^{n}\left|Y_{i}\right| X_{i}\right) /\left(\sum_{i=1}^{n}\left|Y_{i}\right|\right)} \quad \& \quad \sum_{i=1}^{n} \sum_{i=1}^{n}{ }^{3}\right) /\left(\sum_{i}{ }^{2}\right)
$$

are not to converge to a limit.

Thus, either the data are insufficient to yield the true value of the central tendency of annual maximum of the ambient air temperature at Guwahati or the data do not follow the model described by equation (2.1).

\section{Conclusion}

In this study, one method has been searched for determining the true value of the parameter from observed data containing the parameter itself and chance error i.e. from the data following the model described by equation (2.1) since the existing statistical methods of estimation fail in finding out of such value of the parameter in such situation. The method derived here is based on the convergence of statistic i.e. some function of numerical data. 
The method can successfully yield the value of the parameter if the data follow the model described by equation (2.1) and if the data size is sufficient i.e. if the convergence of statistic is achieved. Conversely, if the convergence of statistic is not achieved from the set of data then it implies that either the data do not follow the model described by equation (2.1) or the data size is not sufficient to yield convergence of statistic.

Regarding the findings obtained on annual maximum and annual minimum of ambient air temperature at Guwahati, the following conclusion can be drawn:

(1) The central tendency of Annual Maximum of Ambient Air Temperature at Guwahati can be taken as 37.2 Degree Celsius since all the methods applied have yielded the same numerical results and thus the corresponding data can be treated to follow the model described by equation (2.1).

(2) The central tendency of Annual Minimum of Ambient Air Temperature at Guwahati is not determinable since the methods applied have yielded different numerical results and thus the corresponding data cannot be treated to follow the model described by equation (2.1).

\section{References}

Anders Hald, On the History of Maximum Likelihood in Relation to Inverse Probability and Least Squares, Statistical Science, Vol. 14, pp. 214 - 222, 1999.

Aldrich John, Fisher's Inverse Probability of 1930, International Statistical Review, Vol. 68, pp. 155 $172,2000$.

Barnard G. A., Statistical Inference, Journal of the Royal Statistical Society, Series B, Vol. 11, pp. 115 $149,1949$.

Bordoloi Rinamani Sarmah \& Chakrabarty Dhritikesh, Central Tendency of Annual Extremum of Ambient Air Temperature at Tezpur Based on Midrange and Median, J. Chem. Bio. Phy. Sci. (E- ISSN : 2249 - 1929), Sec. C, 5(4), 4397 - 4410, 2015.

Bordoloi Rinamani Sarmah \& Chakrabarty Dhritikesh, Annual Extremum of Ambient Air Temperature at Dibrugarh: Determination of Central Tendency, J. Chem. Bio. Phy. Sci. (E- ISSN : 2249 - 1929), Sec. D, $6(1), 212-233,2015-16$.

Bordoloi Rinamani Sarmah \& Chakrabarty Dhritikesh, Determination of Parameter from Observation Containing Itself and Chance Error: Central Tendency of Ambient Air Temperature at Tezpur, International Journal of Advanced Research in Science, Engineering and Technology, (ISSN : 2350 0328), 3(1), $1202-1213,2016 a$. 
Bordoloi Rinamani Sarmah \& Chakrabarty Dhritikesh, Determination of Parameter from Observation Containing Itself and Chance Error: Central Tendency of Ambient Air Temperature at Dibrugarh, International Journal of Advanced Research in Science, Engineering and Technology, (ISSN : 2350 0328), 3(8), $2488-2500,2016 b$.

Bordoloi Rinamani Sarmah and Chakrabarty Dhritikesh, Confidence Interval of Annual Extremum of Ambient Air Temperature at Guwahati, Journal of Mathematics and Systems Sciences (ISSN : 0975 5454), 12(1-2), 55-62, 2016c.

Bordoloi Rinamani Sarmah \& Chakrabarty Dhritikesh, Determination of Parameter from Observation Containing itself and Chance Error: Central Tendency of Annual Extremum of Ambient Air Temperature at Dhubri, J. Chem. Bio. Phy. Sci. (E- ISSN : 2249 - 1929), Sec. C, 7(1), 062 - 070, 2016 - 17.

Birnbaum Allan, On the Foundations of Statistical Inference, Journal of the American Statistical Association, Vol. 57, pp. 269 - 306, 1962.

Chakrabarty Dhritikesh, Determination of Parameter from Observations Composed of Itself and Errors, International Journal of Engineering Science and Innovative Technology, 3(2), (ISSN : 2139 - 5967), $304-311,2014 a$.

Chakrabarty Dhritikesh, Analysis of Errors Associated to Observations of Measurement Type, International Journal of Electronics and Applied Research (ISSN : 2395 - 0064), 1(1), 15 - 28, $2014 b$.

Chakrabarty Dhritikesh, Observation Composed of a Parameter and Chance Error: An Analytical Method of Determining the Parameter, International Journal of Electronics and Applied Research (ISSN : 2395 0064), 1(2), $20-38,2014 c$.

Chakrabarty Dhritikesh, Observation Consisting of Parameter and Error: Determination of Parameter, Proceedings of the World Congress on Engineering 2015, (WCE 2015, July 1 - 3, 2015, London, U.K.), ISBN: 978-988-14047-0-1, ISSN: 2078-0958 (Print); ISSN: 2078-0966 (Online), Vol. II, 680 - 684, $2015 a$.

Chakrabarty Dhritikesh, Central Tendency of Annual Extremum of Ambient Air Temperature at Guwahati, J. Chem. Bio. Phy. Sci. (E- ISSN : 2249 - 1929), Sec. C, 5(3), 2863 - 2877, $2015 b$.

Chakrabarty Dhritikesh, Central Tendency of Annual Extremum of Ambient Air Temperature at Guwahati Based on Midrange and Median, J. Chem. Bio. Phy. Sci. (E- ISSN : 2249 - 1929), Sec. D, 5(3), $3193-3204,2015 c$.

Chakrabarty Dhritikesh, Observation Composed of a Parameter and Chance Error: Determining the Parameter as Stable Range, International Journal of Electronics and Applied Research (ISSN : 2395 0064), 2(1), $35-47,2015 d$. 
Chakrabarty Dhritikesh, A Method of Finding True Value of Parameter from Observation Containing Itself and Chance Error, Indian Journal of Scientific Research and Technology, (E-ISSN: 2321-9262), 3(4), $14-21,2015 e$.

Chakrabarty Dhritikesh, Theoretical Model Modified For Observed Data: Error Estimation Associated To Parameter, International Journal of Electronics and Applied Research (ISSN : 2395 - 0064), 2(2), 29 45, 2015f.

Chakrabarty Dhritikesh, Impact of Error Contained in Observed Data on Theoretical Model: Study of Some Important Situations, International Journal of Advanced Research in Science, Engineering and Technology, (ISSN : 2350 - 0328), 3(1), 1255 - 1265, $2016 a$.

Chakrabarty Dhritikesh, Theoretical Model and Model Satisfied by Observed Data: One Pair of Related Variables, International Journal of Advanced Research in Science, Engineering and Technology, (ISSN : 2350 - 0328), 3(2), $1527-1534,2016 b$.

George Marsagilia, Evaluating the Normal Distribution, Journal of Statistical Software, 11(4), 2004.

Ivory, On the Method of Least Squares, Phil. Mag., LXV, 3 - 10, 1825.

Kendall M. G. and Stuart A., Advanced Theory of Statistics, Vol. $1 \& 2,4^{\text {th }}$ Edition, New York, Hafner Press, 1977.

Lehmann Erich L. \& Casella George, Theory of Point Estimation, 2nd ed. Springer. ISBN 0 -387 $98502-6,1998$.

Lucien Le Cam, “ Maximum likelihood - An introduction ”, ISI Review, 58 (2), 153 -171, 1990.

Michiel ed. Hazewinkel, "Normal Distribution”, Encyclopedia of Mathematics, Springer, ISBN 978 - 1 $55608-010-4,2001$.

Walker Helen M. and Lev J., Statistical Inference, Oxford \& IBH Publishing Company, 1965.

Walker Helen M. and Lev J., De Moivre on the Law of Normal Probability, In Smith, David Eugene, 1985. A Source Book in Mathematics, Dover, ISBN 0 - 486 - 64690 - 4, 2, 153 -171, 1990.

Wlodzimierz Brye, The Normal Distribution: Characterizations with Applications, Springer - Verlag, ISBN $0-387-97990-5,1995$. 